\title{
A instituição asilar segundo o cuidador familiar do idoso'
}

\section{The nursing home as seen by the elderly family caretaker}

\author{
Márcia Maria Porto Rossetto Mazza \\ Doutoranda da Faculdade de Saúde Pública da Universidade de \\ São Paulo. E-mail: r.mazza®uol.com.br. \\ Fernando Lefèvre \\ Professor titular do Departamento de Prática de Saúde Pública \\ da Faculdade de Saúde Pública da USP. E-mail: flefevreœusp.br. \\ I 0 presente trabalho é parte da Dissertação de Mestrado: "Cui- \\ dar em família. Análise da representação social da relação do \\ cuidador familiar com o idoso", apresentada ao Programa de \\ Pós-Graduação em Saúde Pública da Faculdade de Saúde Públi- \\ ca da USP, em dezembro de 2002.
}

\section{Resumo}

Este artigo se propõe a descrever as representações sociais de um grupo de cuidadores familiares de idosos sobre o asilo ou a casa de repouso em que eles vivem. 0 universo da pesquisa abrangeu 17 cuidadores familiares, circunscritos na área de abrangência do Centro de Saúde Escola Geraldo Paula Souza da Faculdade de Saúde Pública da USP e participantes do "Projeto Capacidade," (Programa de Assistência ao Idoso no Domicílio, fundamentado num Sistema de Vigilância à Incapacidade Funcional e Dependência). A Metodologia de Pesquisa utilizada foi a qualitativa, e a estratégia metodológica para a análise das entrevistas foi a do Discurso do Sujeito Coletivo (DSC). As representações extraídas dos discursos foram: a família cuida melhor, pois ela impede que o idoso fique deprimido; a família lança mão da institucionalização quando não possui um familiar para cuidar do idoso, e quando o idoso está muito dependente, necessitando de cuidados especiais. A institucionalização é entendida como maléfica, pois provocaria a morte do idoso, não sendo aceita nem pelo idoso nem pelo cuidador. Para muitos desses cuidadores a institucionalização é rejeitada, mas para outros configura uma possibilidade caso o cuidado, por alguma razão, não possa ser executado.

Palavras-chave: Cuidador familiar; Idoso; Família; Asilo. 


\section{Abstract}

The present paper proposes to describe the social representations of a group of elderly family caretakers about nursing homes. The universe of the research encompassed 17 elderly family caretakers within the catchment area of the Centro de Saúde Escola Geraldo Paula Souza of the School of Public Health -USP participants of the Capacidade Project (Program Elderly Home Care, grounded on a Functional Incapability and Dependence Surveillance System). Qualitative methodology was used and the Collective Subject Discourse was the methodological strategy for interview analysis (CSD). The representations drawn from the discourse were: the family provides better care once it prevents the elderly from being depressed, the family resorts to institutionalization when lacking a member to look after the elderly and when he is especially dependent and in need of special care. The institutionalization is seen as malignant for it would lead to the death of the elderly, not being accepted by either the elderly or the caretaker. For many of the caretakers, institutionalization is rejected but for others, it represents a possibility in case the care cannot be provided for some reason.

Key Words: Family Caretaker; Elderly; Family; Nursing Home

\section{Introdução}

\section{0 envelhecimento}

O envelhecimento é um processo universal, evolutivo e gradual, que envolve um somatório de fatores, enfatizando-se os fatores sociais, psíquicos, ambientais e biológicos, que estão intrinsecamente relacionados, e podem acelerar ou retardar esse processo.

Para Papaleo-Neto e Ponte (1996), “...há com o envelhecimento uma diminuição progressiva da capacidade de manutenção do equilíbrio homeostático, que em condições basais, não é suficiente para produzir distúrbio funcional. Quando porém, este declínio é suficientemente grande, ocorre redução importante da reserva funcional colocando o idoso muito próximo da eclosão de sintomas"(p. 7).

Os dados demográficos demonstram um recente e acelerado processo de envelhecimento da população brasileira e apontam que, entre 1960 e 2025, o Brasil passará da $16^{\mathrm{a}}$ para a $6^{\mathrm{a}}$ posição mundial em termos de número absoluto de indivíduos com 60 anos e mais. (Baeta, 1991; Papaleo-Neto \& Ponte, 1996; Paschoal, 1996; Chaimowicz, 1997). Hoje, as pessoas de 60 anos, ou mais, representam $9 \%$ da população, e pelas projeções estatísticas da PNAD, para o ano 2025, essa proporção será de $15 \%$, ou seja, o equivalente a 32 milhões de pessoas, desmentindo cabalmente o fato de sermos um país de jovens (Brasil - MPAS, 200o).

0 processo de envelhecimento populacional brasileiro começou a partir da década de 1960, nas regiões mais desenvolvidas, com o declínio da fecundidade, estendendo-se para as demais regiões e para todas as classes sociais do país (Chaimowicz, 1997). Essa transição epidemiológica e demográfica é decorrente da queda brusca e rápida das taxas de mortalidade e natalidade, com a introdução dos antibióticos, da vacinação, saneamento básico, quimioterápicos, exames complementares, intensificação do uso de anticoncepcionais, etc. (Paschoal, 1996; Silvestre e cols., 1996).

Segundo estudos epidemiológicos, a problemática do idoso no Brasil apresenta-se como um desafio para a Saúde Pública, que exige uma ação imediata no sentido de diminuir as desigualdades, tanto sociais quanto de saúde, nos diferentes estratos dessa população, proporcionando um amparo adequado advindo do sistema público e previdenciário (Brasil MPAS, 2000). 
Como refere Chaimowicz (1997): "O contexto de desigualdade e a velocidade com que ocorrem estas transformações no Brasil apontam para a complexidade crescente nas alternativas de atenção às necessidades desta nova estrutura etária emergente" (p.188).

\section{Idoso saudável, idoso doente, idoso incapacitado: situação e relações intrafamiliares}

Ao caracterizarmos o idoso saudável, doente e/ou com incapacidade, é imprescindível que conheçamos a sua situação familiar, isto é, como se estabelecem as relações intrafamiliares e como se configura a dinâmica de sustentação e de amparo ao idoso.

A esse respeito, Karsch (2002), sustenta que "a família, tradicionalmente considerada o mais efetivo sistema de apoio aos idosos, está passando por alterações decorrentes de mudanças conjunturais e culturais, tanto no Brasil como no mundo" (p. 1)

As mudanças nos padrões demográficos, com a queda da mortalidade e da fecundidade, e o processo de migração das populações mais jovens em direção aos grandes centros, tendeu a enfraquecer o papel da família como provedora de suporte aos idosos (Paschoal, 1996).

Embora a composição das famílias seja de predomínio nuclear (pai, mãe, filhos), observa-se uma forte tendência para o aumento das famílias monoparentais com um número maior de mulheres como chefes (Mioto, 1999).

O número cada vez maior de divórcios e de segundos e terceiros casamentos têm influenciado também a mudança dessa estrutura nuclear e multigeracional (Mioto, 1999; Karsch, 2002), "alterando o perfil de poder e de tomada de decisões dentro das famílias que passam atualmente por uma construção de modelos alternativos de relações e papéis" (Duarte, 1997, p. 228).

Com essa nova composição familiar, onde a mudança de atribuição de papéis experimentada pela mulher, que tradicionalmente era provedora de cuidados para seus familiares, o idoso em particular é o maior afetado.

\section{0 cuidador}

Experiências dos países desenvolvidos cujas populações já vivenciaram o processo de envelhecimento fornecem exemplos de como apoiar as famílias às quais o idoso está presente, necessitando de amparo e de cuidados, tanto no plano da saúde como na manutenção de sua autonomia (no sentido de tomar decisão) e na preservação de sua independência (na realização de atividades de vida diária como: tomar banho, alimentar-se, vestir-se, ir ao banheiro, sentar-se e levantar-se de cadeiras e camas e atividades instrumentais de vida diária como: fazer compras, cuidar das finanças, preparar refeições, arrumar a casa).

Esses países desenvolvidos têm na figura do cuidador, seja ele familiar ou não familiar, ou ainda profissional, um parceiro fundamental no cuidado ao idoso.

"A prática do cuidador não é nova, ela existe há muito no espaço doméstico, com o pressuposto de atenção personalizada e singularizada, voltada às pessoas que inspiram cuidados especiais, como idosos, crianças, portadores de deficiências, entre outras" (Wanderley, 1998, p.5).

Karsch (1998) assevera que "conhecer essa figura oculta aos olhos da sociedade e com ela estabelecer uma parceria deveria ser o passo mais seguro para prestar assistência à saúde nos domicílios.” (p.14)

Entre as várias dimensões no ato de cuidar, podese compreender que as pessoas se comprometem como cuidadores por impulso, como processo natural, dever, obrigação, diferentes graus de ligação afetiva, troca de favores (geralmente os relacionamentos entre mãe e filha) e o temor do asilamento (Wanderley, 1998).

0 perfil do cuidador familiar brasileiro não difere muito do perfil do cuidador de outros países. Geralmente o cuidado é exercido pelos cônjuges e os filhos, particularmente as filhas, geralmente na faixa etária de 45 a 50 anos, sendo solteiras, casadas ou viúvas e geralmente já aposentadas. 0 comum é o cuidador familiar desempenhar suas atividades sozinho, sem a ajuda de ninguém. É chamado de cuidador primário porque tem a responsabilidade total do cuidado (Neri, 1993).

\section{A instituição asilar ou instituição de longa per- manência}

Sem o respaldo familiar, do sistema formal (representado pelo Estado) e com a falta de engajamento da sociedade fica aumentada, para o idoso, a possibilidade de sua inserção em uma instituição asilar.

Evidentemente há idosos que encontram outras possibilidades, que não a instituição asilar, de organizar suas existência e sua vida; há também idosos para os quais a instituição asilar representa uma es- 
colha voluntária que não configura um "mal menor". Mas há muitos idosos para os quais o asilo é "o que sobrou".

Chaimowicz e Grego referem que "os fatores de risco para institucionalização tais como: morar só; ter suporte social precário e baixa renda são cada vez mais freqüentes no Brasil” (p.455).

Segundo os mesmos autores "os idosos residentes nas principais capitais brasileiras apresentam alta prevalência de fatores de risco para a institucionalização: doenças crônico-degenerativas e suas seqüelas, hospitalizações recentes e dependência para realizar as atividades de vida diária (como cuidar da própria higiene, alimentar-se entre outros)" (p.455).

Roose e Buzeki (1999), em pesquisa realizada na cidade de Mar del Plata sobre a institucionalização dos idosos, apontam como fatores de risco: necessidade de cuidados especiais para os idosos com mais de 75 anos, pela maior incidência de demências e deterioração física e cognitiva; mudanças na dinâmica familiar com a introdução da mulher no mercado de trabalho; problemas de habitação: redução e inadequação das mesmas; inexistência de apoio domiciliar exercida por voluntários ou cuidadores profissionais, informação e formação da família, grupos de apoio aos familiares, e ausência de "centros dia" (p.175).

Compartilhando do mesmo raciocínio dos autores anteriormente citados, Telles Filho e Petrilli Filho (2001) dizem que devido às “...condições precárias de saúde, idade avançada e até mesmo distúrbio de comportamento muitos idosos não são capazes de exercer atividades laborais. Nesses casos somando-se as dificuldades financeiras e a falta de respaldo familiar há grande possibilidade de encaminhamento desses indivíduos para instituições asilares” (p.358).

Embora prevaleça entre os estudiosos do envelhecimento a idéia de que o asilamento provoca o isolamento, a baixa auto-estima, entre outros efeitos, há uma corrente que recomenda essas instituições para àqueles idosos que possuem dependência total e impossibilidade de recuperação, levando-nos a considerar o valor social dessas instituições. (Telles Filho e Petrilli Filho, 2001).

Não podemos também negar a importância dessas instituições àqueles idosos que moram sós e que não têm família, pois essas instituições tornam-se um lugar de proteção, e de cuidado.
Pesquisa qualitativa realizada em Santiago de Cuba reforça essa consideração, quando os resultados apontam que os idosos, na sua maioria homens que viviam sós, consideravam a instituição um lugar de proteção, seu verdadeiro lar, a garantia de uma velhice tranqüila. (Bell e cols. 1999).

Isso posto, o objetivo deste artigo, é mostrar as representações sociais, de um grupo de cuidadores familiares de idosos com pequenas incapacidades, sobre o asilo ou casa de repouso.

\section{Método}

O trabalho proposto, em função de seus objetivos e propósitos, implicou a utilização de metodologia de corte qualitativo.

Dentre as técnicas qualitativas, a opção adotada na dissertação que serviu de base para esse trabalho recaiu no Discurso do Sujeito Coletivo (Lefèvre, 2003), obtido através da análise e processamento das entrevistas realizadas com os cuidadores familiares, sujeitos da pesquisa.

O DSC é uma estratégia metodológica quali-quantitativa construída com base na noção de "soma qualitativa” (Lefèvre, 2004), que permite acessar e descrever um conjunto de representações sociais que conformam um determinado imaginário sobre um dado tema.

A população do estudo constituiu-se de cuidadores familiares que coabitavam com idosos de 70 anos, ou mais, com incapacidade funcional.

Estes cuidadores familiares estavam circunscritos na área de abrangência do Centro de Saúde Escola Geraldo de Paula Souza da Faculdade de Saúde Pública - USP, e compunham, junto com os idosos, o universo do Projeto Capacidade desenvolvido através de parceria da Faculdade de Saúde Pública com o Centro de Saúde Escola.

As exigências de inclusão/exclusão no projeto foram: Para o idoso: ter a partir de 70 anos; ser portador de uma ou mais incapacidade funcional (definida pelo Projeto Capacidade) - destes foram excluídos: portadores de mal de Alzheimer; portadores de Mal de Parkinson -; idosos que apresentaram episódio de AVC com prejuízo da cognição; possuir cuidador familiar; não morar só.

Para o cuidador: ter relação de parentesco com o idoso, 
como esposa, filhos, nora, genro, sobrinhos, irmãos, netos; morar com o idoso e ser responsável pelo seu cuidado; atender integralmente o idoso em suas necessidades de saúde.

Para a coleta de dados da pesquisa foi utilizado o instrumental "entrevista aberta semi-estruturada e individual” que, como destaca Simioni (1997), “...são aquelas em que o informante fala livremente sobre o tema proposto, limitado, contudo, por um roteiro de questões a serem pontuadas no momento da entrevista”.

No roteiro de entrevistas utilizado, destacamos, neste artigo, aquele seguimento que se referiu ao enfoque social, (Rossetto-Mazza, 2002), onde o entrevistado expunha sua opinião sobre "O que era para ele colocar o idoso em um asilo ou casa de repouso".

As entrevistas foram realizadas no ambiente domiciliar dos cuidadores, o local onde o cuidado e os relacionamentos aconteciam, tendo como objetivo também evitar constrangimentos, facilitar a oportunidade de entrevista e proporcionar um maior entrosamento entre pesquisador e pesquisado não dando margem a um viés indesejado.

Os depoimentos foram gravados em fita magnética, após a assinatura do Termo de Consentimento Livre e Esclarecido dos entrevistados, e o projeto de pesquisa foi aprovado pelo Comitê de Ética em Pesquisa da FSP/USP.

\section{Resultados e Discussão}

Quanto aos Discursos do Sujeito Coletivo (DSC), foram encontradas oito diferentes representações sociais sobre o asilo ou casa de repouso, isto é, os DSCs foram enquadrados em oito Idéias Centrais que possibilitaram expressar o conteúdo de cada discurso.

As idéias centrais encontradas foram:

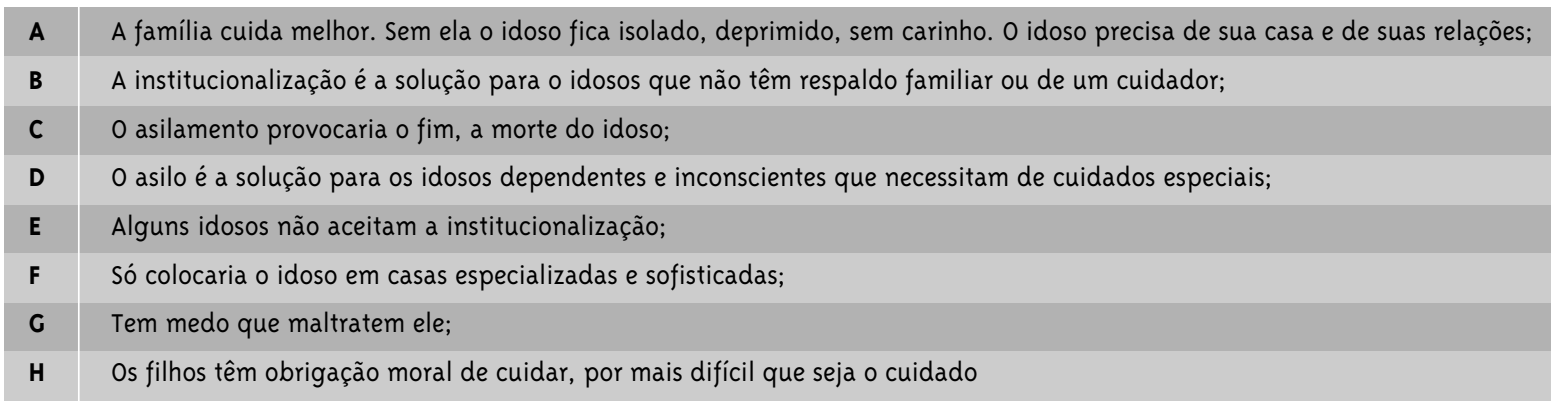

A representação de que a família é ainda a grande provedora de carinho, atenção, amor, dedicação; o local onde o idoso se sente protegido, amparado teve uma freqüência de 7 cuidadores sendo eles: 5 filhas e 2 irmãs.

Quanto à institucionalização ser a solução para os idosos que não têm respaldo familiar ou de um cuidador teve como freqüência 7 cuidadores distribuídos de forma mais diluída sendo eles: 2 filhos, 3 irmãs, 1 genro e 1 nora.

A representação de que o asilamento é maléfico para o idoso pois provocaria o fim, a morte, teve uma freqüência de 4 cuidadores sendo eles: 1 irmã, 1 esposa, 1 genro e 1 filha.

A representação de que alguns idosos não aceitam a institucionalização teve a freqüência de 3 cuidadores. Foram eles: 2 filhos e 1 irmã.
A representação social do asilo ser a solução para idosos dependentes e inconscientes teve 2 freqüências: de 1 nora e de 1 filha.

Nesse discurso fica bastante explícito que o asilo é solução para aqueles idosos que necessitam de cuidados especiais, e a família não possui condições para prestar-lhe esse tipo de assistência. Para esses cuidadores, quando o idoso perde o contato com o mundo e com a família, ou mesmo quando apresenta uma deficiência motora grave, a pessoa que cuida em casa não está capacitada para os cuidados, justificando, desta forma, a internação em casas de repouso que possam realizar tais cuidados.

Uma representação interessante do nosso estudo (com uma freqüência de 2 cuidadores 1 esposo e 1 esposa) foi a que os cuidadores referiram que só colocariam o seu idoso em casas especializadas e sofisticadas 
onde a representação destas casas era de um lugar maravilhoso, um paraíso. É interessante a analogia feita com hotel, onde o idoso disporia de todo conforto e benesses, com a vantagem de possuir todo tipo de assistência necessária para a sua vida.

Finalmente em igual freqüência (de 1 cuidador cada uma) tivemos as representações, onde os cuidadores referiram que os filhos tinham obrigação moral de cuidar dos pais, e os que tinham medo que o idoso fosse maltratado. Para esses cuidadores, prestar cuidados aos pais era um dever de todo filho, não importando como seria executado. Verbalizavam a sua dificuldade no cuidado cotidiano, mas abominavam qualquer possibilidade de asilamento. A possibilidade de o idoso permanecer em um asilo era veementemente descartada pela desconfiança diante do tipo de atendimento prestado, e pela dificuldade de relacionamento deste com as outras pessoas. A única possibilidade de prestação de cuidados para o idoso era o hospital, se ele necessitasse de acompanhamento especializado.

Para melhor visualização das representações sociais encontradas optamos por enquadrá-las em três blocos:

$\mathbf{1}^{\mathbf{0}}$ - A família cuida melhor, pois é ela que impede que o idoso fique deprimido, isolado, sem perspectiva de vida.

$\mathbf{2}^{\mathbf{o}}$ - A família lança mão da institucionalização quando os idosos não possuem respaldo familiar e de um cuidador; estão em situação de alta dependência, necessitando de cuidados especiais; ou poderão arcar com despesas de casas especializadas e sofisticadas, proporcionando um atendimento digno e de qualidade.

$3^{0}$ - A institucionalização é entendida como maléfica, pois poderia provocar o fim, a morte dos idosos, ou quando não é aceita pelos idosos ou pelos cuidadores, pois estes têm medo que os idosos sejam maltrados.

A análise dos DSCs dos cuidadores revela que a família para eles ainda é a maior provedora de cuidados e de respaldo para os idosos, o espaço onde o idoso se encontra protegido e respeitado em seus direitos. Segundo os cuidadores, a família impede a segregação, o isolamento, a depressão e a falta de carinho. Preserva o espaço tanto físico como de relações, favorecen- do desse modo que o idoso tenha resguardada a sua dignidade enquanto ser humano.

Mendes (1998) aventa que: "A atividade de cuidar de um familiar idoso dependente é basicamente desenvolvida no espaço doméstico, espaço este onde parte significativa da vida transcorre, no qual há conhecimento e memória de fatos, relações íntimas e importantes" (p. 179).

A possibilidade de colocação do idoso em casas de repouso é veementemente rechaçada em alguns discursos, acreditando-se que a família que o faz não tem responsabilidade e quer se livrar do idoso.

O DSC abaixo ilustra esta idéia: $\left(^{*}\right)$

"Eu não colocaria em hipótese nenhuma nem no asilo nem na casa de repouso ${ }^{(14)}$. Acho que estar no asilo não é tão bom quanto estar em casa ${ }^{(12)}$, seria uma convivência muito difícil viver num lugar desses ${ }^{(2)}$; mesmo que ele fosse um inválido, eu cuidaria dele. Para mim, pôr no asilo é você isolar a pessoa ${ }^{(16)}$, porque tem familiares que colocam o idoso no asilo e vão lá fazer visitinha, mas ele não quer visitinha porque ninguém cuida melhor do idoso do que sua própria família, não existe isso. Se alguém me falar por $A+B$ que num asilo ou casa de repouso ela vai encontrar pessoas da mesma idade, isso é conversa fiada porque o idoso precisa é de amor, carinho, atenção ${ }^{(17)}$. Então se você está pondo ele no asilo ou instituição é porque você não tem preocupação, você quer se livrar dele. Como vai ficar a vida que ele teve, aqueles 80 , 9o, 70 anos? Onde você vai jogar, no rio? Não pode! No meu modo de pensar, eu não aceito ${ }^{(16)}$, nem em pensamento, nem em sonho(14). Então, igual à família não tem, o idoso se sente jogado nas casas de repouso. Eles fazem o rótulo quando você está lá, depois que você sai é outra história ${ }^{(17)}$. Aqui é o mundo dele, a casa dele $^{(2)}$, aqui ele levou a vida dele, e de repente quando ele não pode mais ficar sozinho, você tira ele da casa dele, das coisinhas dele e coloca em outro lugar? Mesmo que transfira ele e leve um porta-retrato não é a cama dele, não é a casa dele, ele se sente bem, é na casa dele onde ele levou a vida dele ${ }^{(17)}$ "

Born e Abreu (1996) relatam: "O idoso internado em uma instituição ou clínica geriátrica sente-se abandonado...queixam-se de solidão, desenvolvem um

* Todos os DSCs que aparecem neste artigo figuram com os números sobrescritos, com a intenção de indicar a procedência da fala, artifício que revela como os DSCs foram construídos, usando-se falas de sentido semelhante provenientes de depoimentos de diferentes indivíduos. 
quadro depressivo (p.1o) ...a apatia e o desinteresse predominam entre os idosos em instituição...(p.12)."

Outro trecho do discurso em questão que merece destaque é quando os cuidadores discorrem: “...e quando eu ficar velha eu quero ficar como ele. Eu tenho outra formação e os meus sobrinhos também têm essa cabeça. Eu tenho uma sobrinha, ela tem uns 4 ou 5 anos, que fala: "Agora, vó, você vai morrer, não faz mal, depois você volta para a nossa família. A família é isso, vó, você fica velhinha e você fica é com a gente, vó. Você não vai ficar sozinha ${ }^{(16)}$. Então Deus me dê vida para cuidar bastante dele ${ }^{(2)}$."

Dentre as muitas funções da família estão a transmissão de valores, crenças, princípios, e a educação de seus membros. A valorização da pessoa idosa é um processo de construção, um aprendizado que é transmitido para todos os membros de uma cultura, principalmente para as crianças.

Esta representação dos cuidadores aparece em Boechat (1994), que coloca que "os filhos dividam a responsabilidade de sua história e de sua dignidade (...)devemos orientar nossos filhos sobre suas responsabilidades com os idosos, orientação que deveria fazer parte do programa de ensino das escolas (...) Nossas crianças não têm recebido esta mensagem (p. 204).”

A institucionalização é pensada como uma possibilidade para os cuidadores quando a família não possui retaguarda de seus membros, como por exemplo: esposa, filhos, netos, sobrinhos, noras, genros.

Com o atual quadro econômico e social, em que as exigências de sobrevivência são urgentes, as filhas, esposas, enfim os potenciais cuidadores, ingressam no mercado de trabalho, criando uma situação de impossibilidade de manter o idoso junto à família, porque ficaria sozinho e sem a assistência necessária.

O seguinte DSC dos cuidadores revela essa posição:

“A não ser que eu não tivesse ninguém no mundo, se não tivesse filhos nem netos ${ }^{(2)}$, se não tivesse condições para ${ }^{(5,6,11)}$, se ficasse sozinho com ela ${ }^{(15)}$, nesse caso teria que ser tratada ${ }^{(11)}$. Então depende muito da situação da família, porque se tem um único filho ou filha que trabalha e a pessoa vai ficar sozinha, é preferível estar numa casa de repouso pelo fato de ter pessoas da mesma idade conversando ${ }^{(4,9)}$, ter medicamento na hora certa, ter um espaçozinho para andar. Dentro de casa a pessoa não tem com quem falar, o dia todo fica assim encucada, é ruim( ${ }^{(4)}$. Uma pessoa de idade precisa ter alguém que tenha uma dedicação, um cuidado, que esteja ali mais ou menos próximo para estar toda hora atento, porque se você deixar ela não come, não toma remédio(4), se cai um tombo precisa de uma emergência e ter quem socorra ${ }^{(9)}$ então é complicado(4). Eu converso sempre com ela, vamos supor que eu morra primeiro, você tem que ir para um asilo porque suas noras têm o serviço delas, têm os filhos, seus filhos trabalham, o cotidiano de todo mundo $^{(11)}$. Então eu acho que tudo depende da situação da família: para uma pessoa de idade ficar sozinha o dia inteiro é preferível estar numa casa de repouso do que estar com a família ${ }^{(9) \text { " }}$

Esse discurso ilustra o que afirmam Leme e Silva (1996) sobre a síndrome de insuficiência familiar: “Com a progressiva diminuição do tamanho das famílias, gerando a síndrome do filho único, seus membros ficam impossibilitados de prestar assistência necessária a seus idosos, pois necessitam trabalhar, não podendo dar atenção em tempo integral que o caso exige" (p.96).

Reforçando essas considerações de autores e cuidadores, podemos apontar o que Silva (1996) retrata sobre o assunto: “...parece que o relacionamento positivo pais-filhos se desenvolve melhor nas famílias onde a atenção parental e as demandas são compartilhadas entre mais filhos...o tamanho da família pode vir a ser um preditor importante da avaliação do nível de cuidados individuais para o idoso no futuro (p.77).”

0 asilo ou casa de repouso fica sendo o único recurso social das famílias pobres que não podem cuidar de seus idosos dependentes e incapacitados (Gonçalves e cols, 1990).

A institucionalização passa a ser um "mal necessário": pelo menos os idosos estarão sendo assistidos, cuidados, e teriam a companhia de outras pessoas.

Desse modo, verificamos também que a institucionalização se faz necessária para os cuidadores familiares em questão, quando os idosos são dependentes e inconscientes, necessitando de cuidados especiais aos quais os cuidadores não se sentem capacitados fisicamente, emocionalmente e tecnicamente.

Os idosos, ao apresentarem tais deficiências e dependências, livram os cuidadores da culpa pela institucionalização, uma vez que o cuidado deverá ser executado por profissionais capacitados, que no seu imaginário são os que melhor desempenharão a assistência de que o idoso necessita. 
Assim, a institucionalização não é vista como um abandono do idoso, mas sim como um meio de assistência adequada para ele.

Born e Abreu (1996) ratificam que os diagnósticos mais comuns encontrados nas instituições são: mal de Alzheimer, mal de Parkinson, AVC, problemas psiquiátricos, incontinência urinária e fecal, e úlcera de pressão.

A representação obtida através destes depoimentos é rica de significados:

"Eu acho superválido principalmente ${ }^{(9)}$ se for em último caso, se precisasse de cuidado especial ${ }^{(9,10)}$, se chegasse no estado que a pessoa não tenha mais condição motora ${ }^{(9)}$, não estiver mais andando ${ }^{(10)}$, se tiver que tomar remédio, injeção, ficar chamando o farmacêutico, contratar alguém para ficar, para fazer curativo. Teria que ter cama própria, quando não tem mais jeito de dar banho, as enfermeiras têm que dar banho na cama ${ }^{(10)}$. Enquanto a pessoa está consciente, conhecendo o pessoal da casa, dá para ir levando ${ }^{(10)}$. Agora se a pessoa estiver esclerosada, tanto faz eu como você estar aqui, em casa, não conhece mais ninguém, a pessoa não iria sofrer. Quando a pessoa está nessa situação já está pra lá de Bagdá(1o), então é preferível até em uma casa de saúde ${ }^{(10)}$, porque você não vai agüentar cuidar, vai ser desconfortável para a própria pessoa porque você não é especializada e tem determinadas horas que você precisa de um tratamento especializado, num cômodo com enfermagem ${ }^{(9)}$. Agora eu acho se você põe, você tem que fazer no mínimo, no mínimo como eu fazia com a tia do meu marido que vivia aqui conosco, ela teve dois espasmos cerebrais, ficou na cama totalmente, não falava, não conhecia ninguém. Eu ia visitá-la de segunda, quarta e sextafeira em horários diferentes para saber se realmente estava sendo bem cuidada. Eu sei que ela sabia que eu ia, o corpo não sabia mas o espírito dela sabia. Isto é para a pessoa saber que ela não está com você, mas você continua pensando nela ${ }^{(9)}$ ".

Ao contrário do exposto anteriormente, foi possível extrair outra representação de institucionalização onde esta é sofisticada e altamente especializada, feita num lugar onde o idoso e mesmo o cuidador pudessem usufruir de todo conforto, assistência médica e tecnológica avançada.

A representação dessas casas de repouso é comparada a um hotel, um "lugar maravilhoso", "um paraíso", lugar inacessível ao padrão de vida dos cuidadores.

"Inicialmente eu sou contra, absolutamente não passa pela minha cabeça, mas eu colocaria ${ }^{(1)}$ se fosse em uma clínica ${ }^{(13)}$, a melhor clínica que houvesse em São Paulo para cuidar ${ }^{(1)}$.Um lugar desses ${ }^{(1)}$ é como um hotel, só que tem assistência, assistência social, enfermeiros, médicos, tudo isso é bom demais, mas deve ser muito caro $^{(13)}$, nesse momento não há condições, não tenho nenhuma ${ }^{(1)}$, é coisa pra gente rica mesmo, não para $\operatorname{mim}^{(13)}$. Eu já ouvi falar, mas eu não conheço, às vezes aparece na televisão, em certas novelas, lugares maravilhosos, parece um paraíso. Aquele jardim imenso, aquele parque imenso, a gente vê aquelas enfermeiras cuidando, já pensou toda essa mordomia, eu ia junto, ficar sentada naqueles bancos ali no parque, que coisa maravilhosa, é bom demais ${ }^{(13)}$.

Para os cuidadores familiares, outra representação permeada de significado emocional é a referência ao suposto malefício que uma institucionalização provocaria ao idoso.

No imaginário destes a institucionalização é geraria tanto no idoso como no cuidador seqüelas e comprometimentos negativos, pois provocaria o seu fim, não sendo aceita nem pelo idoso nem pelo cuidador.

As justificativas mencionadas são que os idosos se sentiriam sozinhos, tristes, deprimidos, abandonados, sucumbindo mais rápido. 0 fato de terem tido exemplos anteriores na família e entre amigos reforça a percepção negativa que tal atitude desencadearia na família. Acreditam que quando o idoso se mantém afastado dos familiares, internados em uma instituição, que na maioria das vezes é inadequada e insuficiente, não será cuidado com carinho e dedicação.

Essa situação é reforçada pelo próprio idoso, que não aceita a possibilidade de uma internação, preferindo "morrer na rua" a se submeter a uma institucionalização.

Trechos dos discursos podem ilustrar nossas considerações:

"Eu jamais colocaria ${ }^{(15,17)}$, ela se sentiria sozinha ${ }^{(6,13,15)}$, isolada ${ }^{(15)}$, triste, abandonada ${ }^{(15)}$, e morreria mais depressa ${ }^{(13,15,17)}$. Seria o fim dela ${ }^{(15)}$. Então, por mais trabalho que dá cuidar eu não poria ${ }^{(6)}$, o tratamento não é igual. Não faz muito tempo ${ }^{(6,13,15,17)}$ nós fomos visitar a minha tia e nós saímos de lá arrasados ${ }^{(15)}$ porque ela se sentia só, chorava ${ }^{(6)}$, implorava, pedia pelo amor de Deus para tirar ela de lá(15). 0 ambiente 
era assim modesto, não tinha muita higiene, você sentia cheiro de urina quando entrava. Eu via que era um pouco abandonado e eu não gostei nada do que eu vi ${ }^{(13)}$. A família inteira brigou e ficou revoltada com as minhas primas e não entendia o porquê puseram a mãe lá. Eu só sei que foi muito triste, foi uma bagunça na família inteira ${ }^{(15)}$. Nesses asilinhos morre em uma semana ${ }^{(13)}$. Eu não colocaria, não, porque ela é bem lúci$\mathrm{da}^{(3)}$, eu acho que ela teria uma resistência muito gran$\mathrm{de}^{(4)}$, ela até morreria ${ }^{(11)}$. Agora ela parou de falar nisso, mas um pouquinho mais para trás ela falava assim: 'Eu estou vendo que um dia vocês vão me jogar num asilo, mas eu já vou avisar, se vocês me puserem no asilo eu prefiro morrer ${ }^{(3)}$, eu fujo e vou morrer na rua $^{(11)}$ '. Deus me livre a minha mãe parar num asilo, nunca $^{(3)}$. Fico aqui com ela, mas para lá, não ${ }^{(3)}$ Eu tenho preocupação e medo do que pode acontecer, dele estar longe, não saber o que está acontecendo, e dependendo do lugar acho que pode acontecer de tudo, até o pior, e num lugar assim eu teria muito medo dele sofrer, alguém fazer algum mal, entende? ${ }^{(8)}$ "

Para finalizar esta discussão, gostaríamos de salientar que a riqueza de detalhes presentes nesses depoimentos só foi possível de ser alcançada através das visitas domiciliares, no ambiente natural, ou seja, no domicilio desses cuidadores, onde as representações e os significados associados ao ser cuidador de idosos fragilizados emergiu de uma forma intensa e permeada de sentimentos.

Concordamos novamente com Karsch (1998) quando postula: "Conhecer esta figura oculta aos olhos da sociedade e com ela estabelecer uma parceria deveria ser o passo mais seguro para prestar assistência à saúde nos domicílios (p.14), lócus onde o cuidado acontece sem quase nenhuma orientação que a situação de dependência exige (p.13).”

\section{Considerações Finais}

O envelhecimento populacional brasileiro é uma realidade que se apresenta concreta e crescente, fazendo com que a adoção de políticas e medidas específicas de assistência social e de saúde se façam urgentes, com vistas a propiciar a manutenção da família enquanto unidade essencial provedora de cuidados ao idoso, seja ele autônomo e independente ou com pequenas fragilidades e dependente.
Mas isso nem sempre é possível. Assim, considerando também a crescente fragilização da família, a institucionalização não pode deixar de ser considerada.

Nessa linha, as diferentes representações que pudemos extrair dos depoimentos nos levam a pensar que, se para muitos desses cuidadores a institucionalização é rejeitada, para outros ela se configura como uma possibilidade a não ser descartada caso o cuidado fique impossibilitado de ser executado.

A necessidade de intensificação de esforços no sentido de amparar essas famílias na extensão de serviços do tipo: atenção domiciliar, suporte médico e de equipe multiprofissional, sistema efetivo de referência e contra-referência às instâncias mais especializadas, com a realização de exames e a retaguarda hospitalar, quando necessária, são ao nosso ver ações importantes para ajudar esses cuidadores a diminuir o stress a que estão submetidos, diminuindo com isso a internação desnecessária ou não desejada.

\section{Referências}

BAETA, A. M. C. Transição demográfica e novas demandas em saúde: o atendimento à terceira idade. $R e$ vista de Administração Pública, Rio de Janeiro, v.25, p.173-8, 1991.

BELL, B. S.; GIRON, D. M. B.; FIGEROLLI, Y. M. e ANGLADA, M. Z. Aspectos psicologicos y sociales más relevantes en ancianos institucionalizados. Revista Cubana de Enfermeria, Havana, v.15, n.3, p. 207-12, 1999.

BOECHAT, N. S. Asilamento: uma visão. In: PEREIRA, S. E. M. (Org.). Caminhos do envelhecer. Rio de Janeiro; Revinter; 1994; p.199-205.

BORN, T. ; ABREU, C. M. G. de. O cuidado ao idoso em instituição de longa permanência. Gerontologia, São Paulo, v.4, n.4, p.7-14, 1996.

BRASIL. Ministério da Previdência e Assistência Social. Secretaria de Estado e Assistência Social. Programa Nacional de Cuidadores de Idosos. Brasília (DF), 2000.

CHAIMOWICZ, F. A saúde dos idosos brasileiros às vésperas do século XXI: problemas, projeções e alternativas. Revista de Saúde Pública, São Paulo, v.31, p.184-200, 1997. 
DUARTE, Y. A. de O. Cuidadores de idosos: uma questão a ser avaliada. Mundo da Saúde, São Paulo, v.21, p.226-30, 1997.

GONÇALVES, L. H. T. et al. Rede de apoio comunitário à família do idoso. Rev Ciências da Saúde, v.9, p.86101, 1990.

KARSCH, U. S. M. (Org.). Envelhecimento com dependência: revelando cuidadores. In: ___ Introdução. São Paulo: EDUC, 1998. p. 13-9.

KARSCH, U. S. M. Apoio familiar aos idosos. São Paulo; 2002. [Paper distribuído no Programa de Verão: Promoção da Saúde no Envelhecimento: contribuição da epidemiologia (PSE) da Faculdade de Saúde Pública da USP]

LEFÈVRE, F. e LEFÈVRE, A. M. C. (Orgs.). O discurso do sujeito coletivo: um novo enfoque em pesquisa qualitativa (Desdobramentos). Caxias do Sul: EDUCS, 2003.

LEFÈVRE, F. e LEFÈVRE, A. M. C. O discurso do sujeito coletivo: teoria e prática. São Paulo, 2002. [Paper distribuído no Programa de Verão: Pesquisa qualitativa: novas metodologias de análise de discurso] Faculdade de Saúde Pública, Universidade de São Paulo.

LEFÈVRE, F. e LEFÈVRE, A. M. C. Soma qualitativa. Disponível em: www.fsp.usp.br/quali-saude. Acesso em: abril de 2004 .

LEME, L. E. G.; SILVA, P. S. C. P. da. O idoso e a família. In: PAPALÉO NETO, M. (Org). Gerontologia. São Paulo: Atheneu, 1996. p.92-7.

MENDES, P. M. T. Cuidadores: heróis anônimos do cotidiano. In: KARSCH, U.M.S. (Org.). Envelhecimento com dependência: revelando cuidadores. São Paulo, EDUC; 1998. p.147-70.
MIOTO, R. C. T. Famílias hoje: o começo da conversa Texto Contexto Enfermagem. v. 8, p. 211-19, 1999.

NERI, A. L. Bem-estar e estresse em familiares que cuidam de idosos fragilizados e alta dependência. In: NERI, A. L. (Org.). Qualidade de vida e idade madura. Campinas: Papirus, 1993. p. 237-85.

PAPALÉO NETO, M. e PONTE JR. Envelhecimento: desafio na transição do século. In: PAPALÉO NETO, M. (Org.). Gerontologia. São Paulo: Atheneu, 1996. p.3-12.

PASCHOAL, S. M. P. Epidemiologia do envelhecimento. In: PAPALÉO NETO, M. (Org.). Gerontologia. São Paulo, Atheneu, 1996. p.26-43.

SILVA, E. B. N. A relação familiar e o idoso. Gerontologia, São Paulo, v.4, n.2, p.75-8, 1996.

SILVESTRE, J. A. et al. O envelhecimento populacional brasileiro e o setor saúde. Arquivos de Geriatria $e$ Gerontologia. Rio de Janeiro, n.1, p.81-9, 1996.

SIMIONI, A. M. C. et al. Metodologia qualitativa nas pesquisas em saúde coletiva: considerações teóricas e instrumentais. In: Eixo de Política Planejamento e Administração. Departamento de Prática de Saúde Pública da Faculdade de Saúde Pública da USP, 1997. (Série Monográfica n. 2).

WANDERLEY, M. B. (Coord.). A publicização do papel dos cuidadores domiciliares: uma questão em debate. São Paulo: Instituto de Estudos Especiais PUC, 1998. 